\title{
Design and Fabrication of W-Band Waveguide Slotted Array Antenna Based on Milling Process
}

\author{
Hongfu Meng $\mathbb{D}$, Yang Chen, and Wenbin Dou \\ State Key Laboratory of Millimeter Waves, Southeast University, Nanjing 210096, China \\ Correspondence should be addressed to Hongfu Meng; menghongfu@163.com
}

Received 22 October 2019; Revised 3 January 2020; Accepted 17 January 2020; Published 14 February 2020

Academic Editor: Gino Sorbello

Copyright (c) 2020 Hongfu Meng et al. This is an open access article distributed under the Creative Commons Attribution License, which permits unrestricted use, distribution, and reproduction in any medium, provided the original work is properly cited.

\begin{abstract}
A single-layer waveguide slotted array antenna is proposed for $\mathrm{W}$-band applications. To eliminate the alignment errors, all structures including the radiation slots, radiation waveguides, and power divider network are realized in one layer based on the milling process, and a planar metal plate is employed to cover the bottom. For example, an $8 \times 9$ array is designed with 1 -to- 8 power divider network to validate the proposed technology. The effective radiation aperture size of the array is $24 \mathrm{~mm} \times 21 \mathrm{~mm}$, and the height is only $8 \mathrm{~mm}$. The measured reflection coefficient of the antenna is larger than $3 \mathrm{GHz}$ for $\left|S_{11}\right|<-10 \mathrm{~dB}$. The peak gain is $25.9 \mathrm{dBi}$, and the corresponding antenna efficiency is about $65 \%$. All cross-polarization of the antenna array is less than $-35 \mathrm{~dB}$. The proposed array antenna features a simple structure, low cost, and easy implementation for W-band applications.
\end{abstract}

\section{Introduction}

Antenna array is widely used in microwave engineering system, such as the microstrip antenna array, because of the high efficiency, simple structure, and low cost. When the frequency increases to millimeter-wave band, the microstrip antenna suffers from high dielectric loss and leakage loss which result in a low radiation efficiency [1-3]. The substrate-integrated waveguide (SIW) antenna is proposed for Ka-band and W-band applications [4-9]. The dielectric loss of the SIW antenna is acceptable at Ka-band [5]. However, at $\mathrm{W}$-band, the radiation efficiency is seriously declined as the loss of the network is increasing [7].

Compared with SIW, the waveguide slotted array is an excellent candidate for millimeter wave antenna array as there is no dielectric loss. Many waveguide slotted arrays at Ka-band have been designed with very good radiation performances [10]. These waveguide slotted arrays are always designed with the feed network, radiation waveguides, and radiation slots in different layers. The different layers need to be fabricated separately, and a very high precision assembly technology is required to assemble all the layers together. However, the design, fabrication, and assembly of the multilayer waveguide slotted array at W-band are very difficult.
Several technologies are proposed in the literature for $\mathrm{W}$-band arrays. The diffusion bounding of the laminated thin metal technique is used to fabricate the waveguide slotted array at $\mathrm{W}$-band. The radiation slots and feed waveguide are etched on two different plates and connected together by diffusing bounding for high precision assembling [11]. The electroforming process is also proposed to fabricate the waveguide slotted array at $\mathrm{W}$-band with very high radiation efficiency [12]. The silicon process is proposed for the corporate-feed waveguide slotted array at $350 \mathrm{GHz}$ [13]. All the processes are very expensive.

In this paper, an $8 \times 9$ waveguide slotted array at $\mathrm{W}$-band based on the milling process is presented. The power divider network, the radiation waveguides, and the radiation slots of the antenna are designed in a single layer, so the high fabrication precision can be achieved by milling process, and the assembly is very easy.

\section{Antenna Design}

2.1. Antenna Structure. The structure of the proposed waveguide slotted array is shown in Figure 1. The antenna consists of two parts, part 1 and part 2 . All the 1-to- 8 power divider network, 8 radiation waveguides, and $8 \times 9$ radiation 


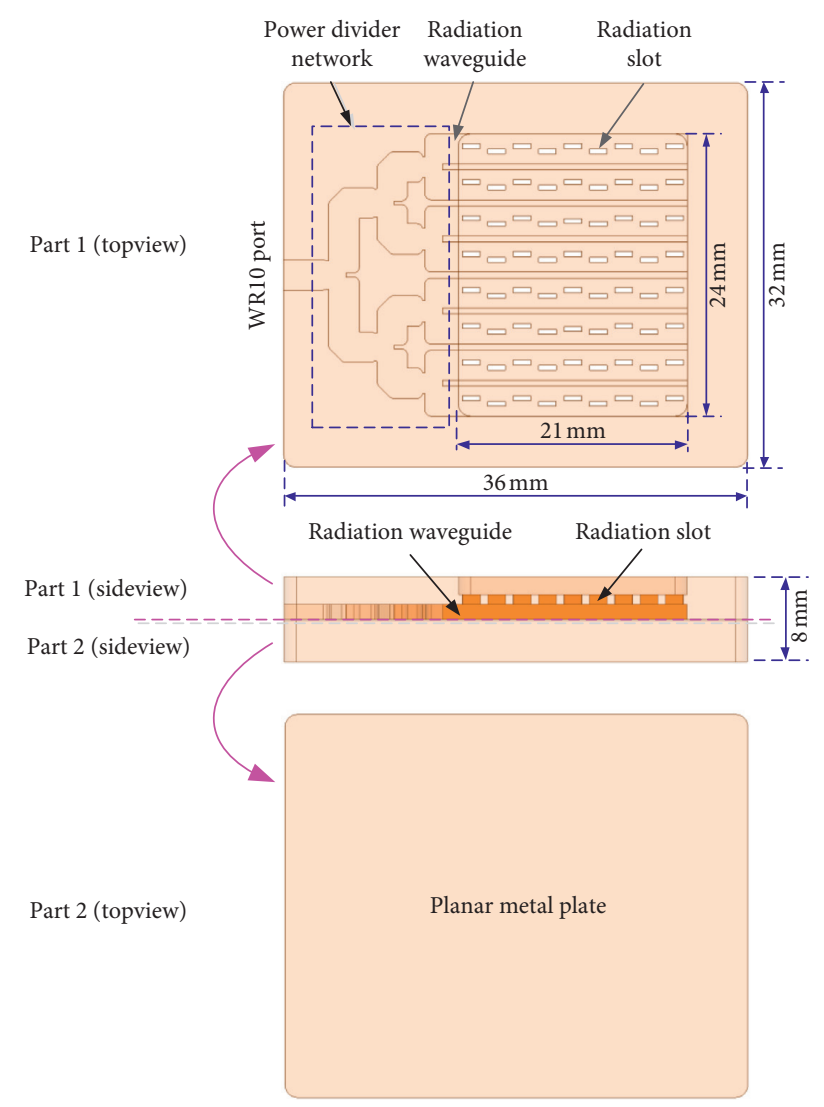

FIGURE 1: Structure of proposed waveguide slotted antenna.

slots are in part 1 , and part 2 is a planar metal plate as a cover. Thus, only one layer (part 1) needs to be fabricated with high precision, and there is no high precision aligning requirement when assembling the two parts together. So, it can be named as single-layer waveguide slotted array antenna. The total size of the antenna is $36 \mathrm{~mm} \times 32 \mathrm{~mm}$, while the effective radiation aperture size is $24 \mathrm{~mm} \times 21 \mathrm{~mm}$. The metal wall surrounding the effective radiation aperture is employed for assembling connection, and it has little effect on the radiation performance of the antenna. The thickness of the antenna is only $8 \mathrm{~mm}$. The antenna is fed by a WR10 waveguide port of at the left side.

2.2. Power Divider. In the power divider network, there are three stages of 1-to-2 waveguide power divider as shown in Figure 2 . The $1^{\text {st }}$ and $2^{\text {nd }}$ stages have the same parameters, and the last stage is designed separately as the two output waveguides are very close.

In each 1-to-2 power divider, two structures are employed to split the power and adjust the impedance matching. One is the ridge opposite the input waveguide, which is used to divide the power into two equal parts, and the other is the inductive window in the input waveguide, which is used for adjusting the input matching. For the designed 1-to-8 power divider, the parameters of the ridge and matching window of the $1^{\text {st }}$ and $3^{\text {rd }}$ stages are given in Table 1.

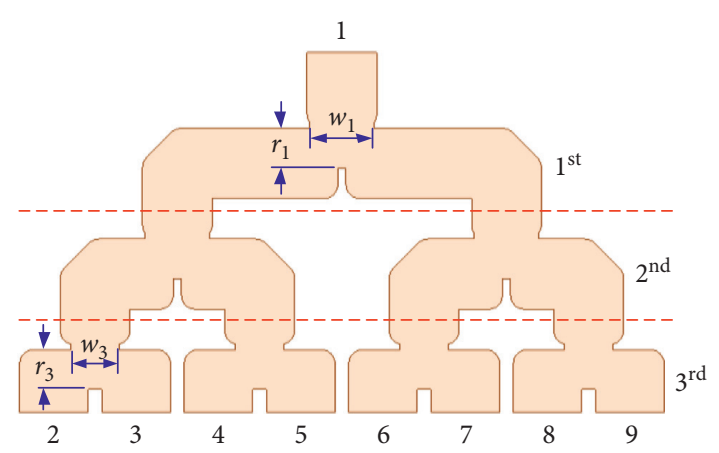

FIgURE 2: Structure of the 1-to-8 power divider.

TABLE 1: Geometrical sizes of the power dividers.

\begin{tabular}{lcccc}
\hline Parameter & $w_{1}$ & $r_{1}$ & $w_{3}$ & $r_{3}$ \\
\hline Size $(\mathrm{mm})$ & 2.20 & 1.54 & 1.68 & 1.64 \\
\hline
\end{tabular}

The whole power divider network is simulated using Ansys HFSS, and the results are shown in Figure 3. The reflection coefficient $\left|S_{11}\right|$ at the input port 1 of the network is below $-15 \mathrm{~dB}$ from $90 \mathrm{GHz}$ to $96 \mathrm{GHz}$. At the output ports $2-9$, the magnitude difference of $\left|S_{n 1}\right|$ is less than $0.2 \mathrm{~dB}$, and the phase difference is less than $3^{\circ}$, where $S_{n 1}$ is the transmission coefficient from port 1 to port 2-9.

2.3. Radiation Slot. In the radiation waveguide, when an offset longitudinal slot etched on the broadside of the waveguide, the electromagnetic field can radiate from the slot. In order to realize the designed aperture field distribution on the antenna aperture, the leak power of every slot must be designed carefully. The key consideration of the waveguide slotted array design is the size and location of each slot on the aperture.

The longitudinal slot etched on the broadside of the radiation waveguide can be equivalent to normalized shunt admittance $y=g+j b$ on two ports' transmission line [14], as shown in Figure 4. If the waveguide is end-fed and all radiation slots are in the same size, the total normalized admittance $G$ of shunt slots in the radiation waveguide is given by

$$
G=n y=\frac{1-S_{11}}{1+S_{11}}
$$

where $n$ is the total slot number in the radiation waveguide and $S_{11}$ is the reflection coefficient at the feed port.

The slots are assumed to be resonant, while the imaginary part of $S_{11}$ equals to zero. Evidently, the obtained $y$ is an average value. Figure 5 shows the curve about the resonant length $l$ against the slot offset distance $\mathrm{d} x$ to the central line of the radiation waveguide at the center frequency $93 \mathrm{GHz}$. It can be found that the resonant length of the slot becomes longer as the slot offset increases.

In the design, the slot width $w$ is $0.4 \mathrm{~mm}$, and the width of the radiation waveguide is $2.25 \mathrm{~mm}$; therefore, the guided-wavelength $\lambda_{\mathrm{g}}$ in the radiation waveguide is $4.6 \mathrm{~mm}$. Thus, the distance between each slot in the 


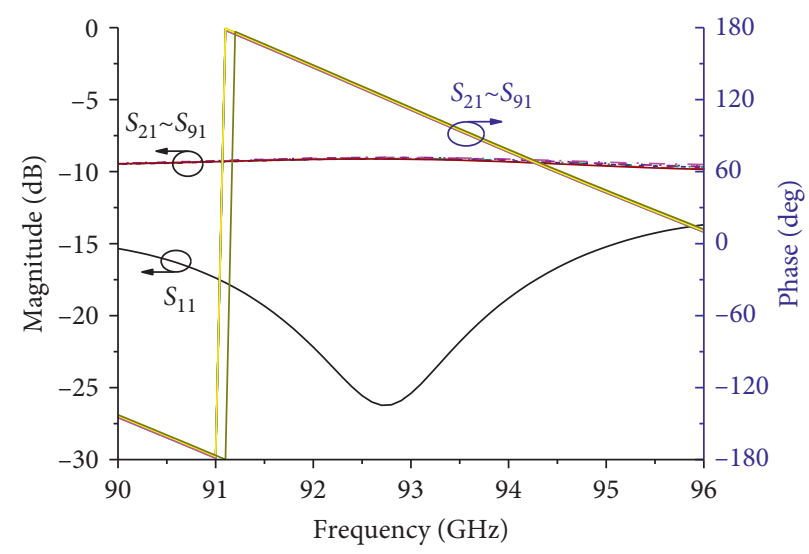

Figure 3: Simulated S-parameter of the 1-to-8 power divider.
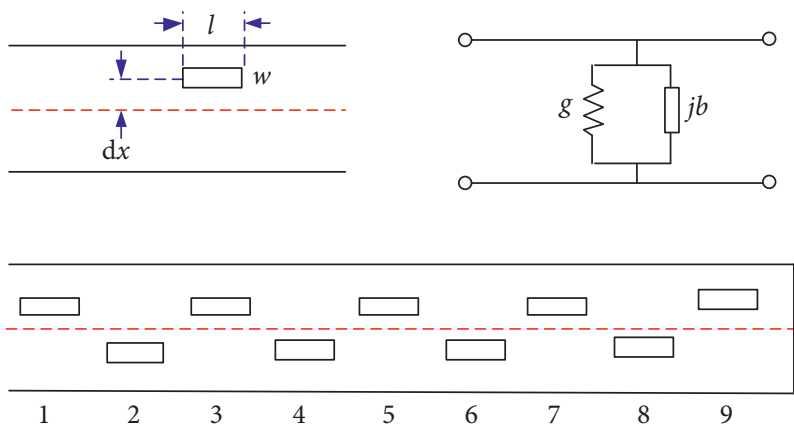

FIgURE 4: Waveguide slot and equivalent circuit model.

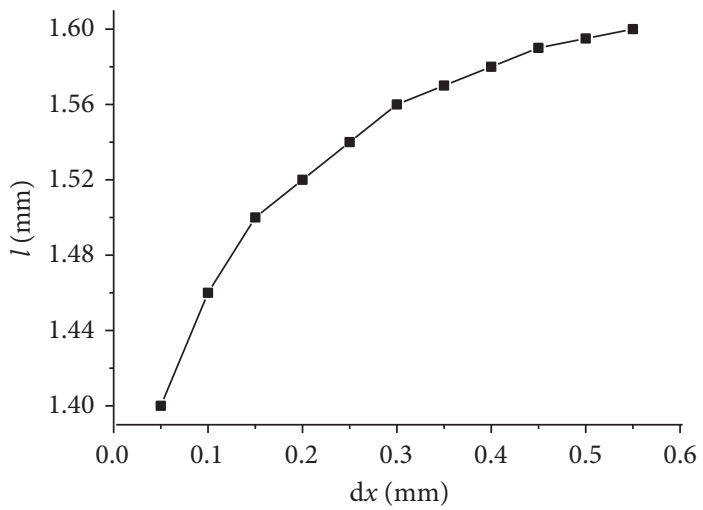

Figure 5: Parameter extraction curve of the resonant length $l$ versus the slot offset distance $\mathrm{d} x$.

waveguide is $\lambda_{\mathrm{g}} / 2=2.3 \mathrm{~mm}$. By using Elliot's theory in [15] and the resonant relationship in Figure 5, the parameters of radiation slots in each radiation waveguide can be calculated and are given in Table 2 .

\section{Results and Discussion}

The designed waveguide slotted array at W-band is fabricated with gold-plated brass using the milling process. The corner radius of the radiation slot is $0.2 \mathrm{~mm}$, and the corner radius in the rectangular waveguide is $0.3 \mathrm{~mm}$. Since all the
TABLE 2: Geometrical sizes of the radiation slots in the radiation waveguide.

\begin{tabular}{lccccccccc}
\hline Slot no. & 1 & 2 & 3 & 4 & 5 & 6 & 7 & 8 & 9 \\
\hline $\mathrm{d} x(\mathrm{~mm})$ & 0.20 & 0.30 & 0.25 & 0.25 & 0.25 & 0.25 & 0.25 & 0.30 & 0.35 \\
$l(\mathrm{~mm})$ & 1.52 & 1.56 & 1.54 & 1.54 & 1.54 & 1.54 & 1.54 & 1.56 & 1.57
\end{tabular}

power divider network, radiation waveguides, and radiation slots are in part 1, only this part need to be fabricated by milling process and the fabrication accuracy can reach 


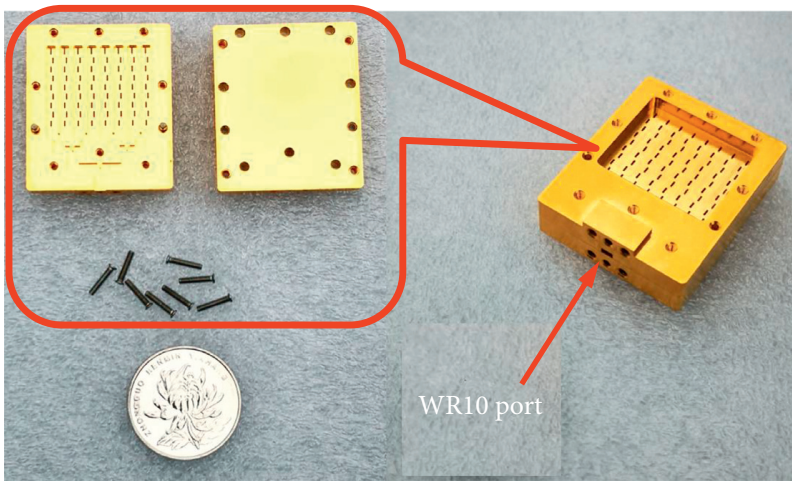

Figure 6: The fabricated layers by milling process and the assembled antenna.

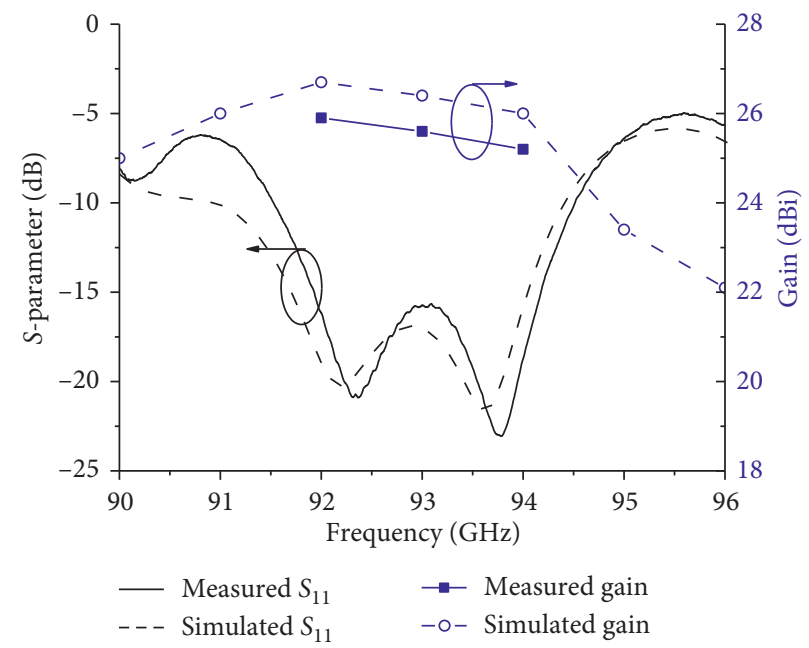

Figure 7: Measured and simulated reflection coefficient and gain of the antenna.

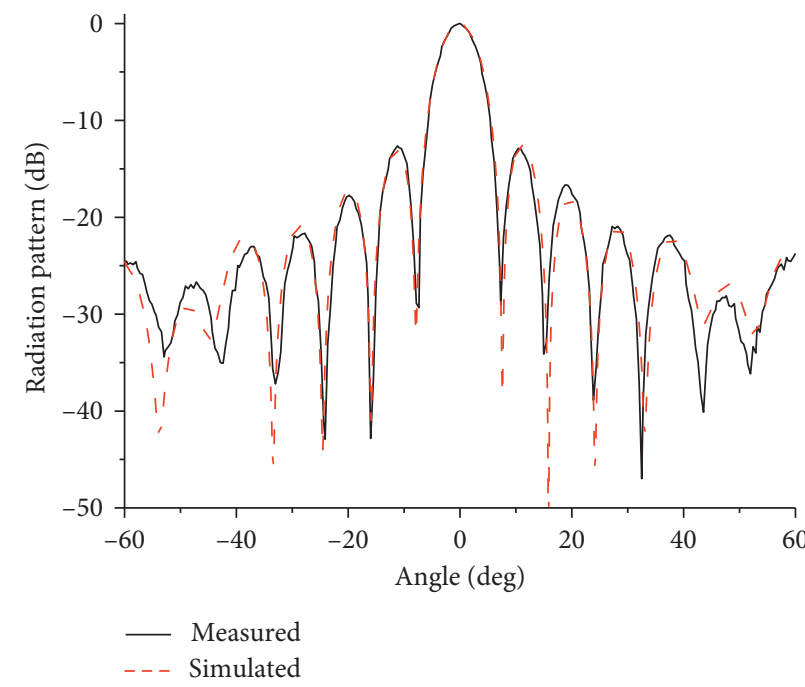

(a)

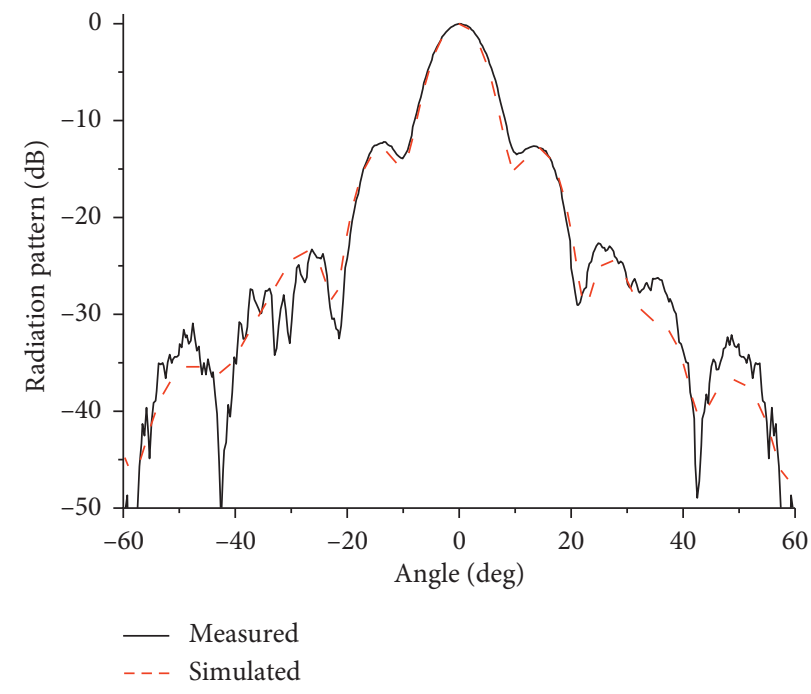

(b)

FIGURE 8: Measured and simulated radiation patterns of the antenna at $93 \mathrm{GHz}$ : (a) E-plane and (b) $H$-plane. 


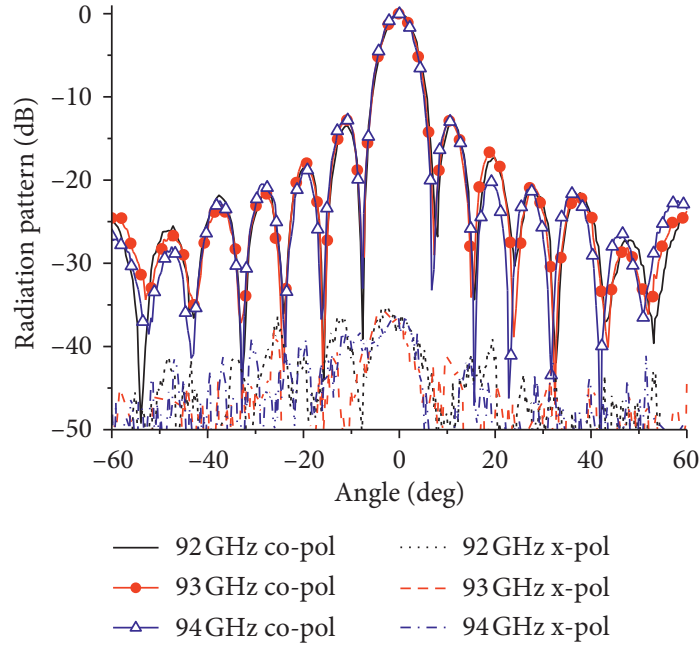

(a)

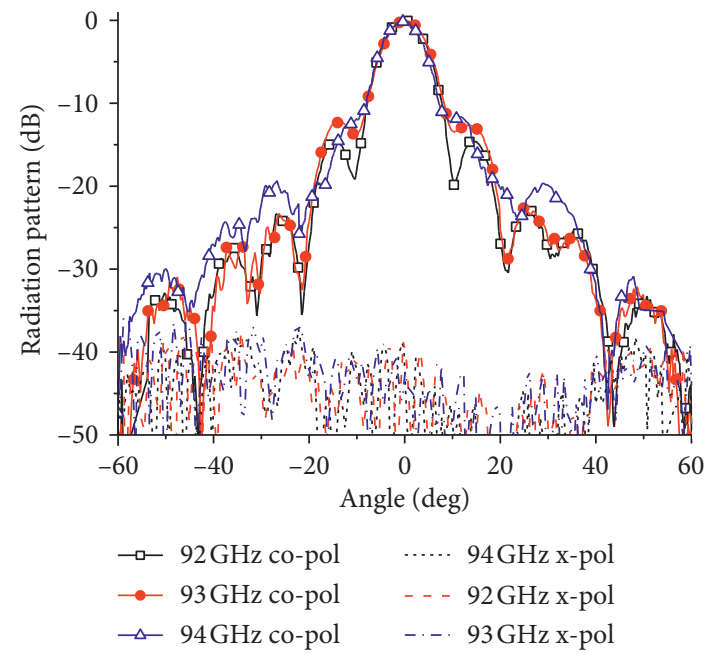

(b)

Figure 9: Measured radiation patterns of the antenna at different frequencies: (a) E-plane and (b) $H$-plane.

$\pm 0.02 \mathrm{~mm}$. Part 2 is a planar metal plate. The prototype of fabricated antenna is shown in Figure 6. The two parts are shown in the left, and the assembled sample is shown in the right. 8 screws are placed at the outside of the effective radiation aperture for assembling connection. The WR10 feed port on the side is also shown.

Firstly, the antenna is simulated using Ansys HFSS. The reflection coefficient at the feed port and gain of the antenna are shown Figure 7. The reflection coefficient is below $-10 \mathrm{~dB}$ within $91-94.5 \mathrm{GHz}$. The peak gain is about $26.7 \mathrm{dBi}$ at $92 \mathrm{GHz}$ with the aperture efficiency $79 \%$.

Then, the reflection coefficient of the antenna is measured using the vector network analyzer Agilent E8363C with frequency extension module. The gain and the radiation patterns are measured in anechoic chamber with the signal generator Agilent E8257D with frequency multiplier as the source and the spectrum analysis Agilent N9030A with frequency mixer as the receiver. In Figure 7, the measured reflection coefficient $\left|S_{11}\right|$ at feed port of the antenna is below $-10 \mathrm{~dB}$ from $91.5 \mathrm{GHz}$ to $94.5 \mathrm{GHz}$, which is very close to the simulated one. The peak gain is about $25.9 \mathrm{dBi}$, and the corresponding antenna efficiency is about $65 \%$. The measured gains at 92,93 , and $94 \mathrm{GHz}$ are also given, and there are only $0.8 \mathrm{~dB}$ gain differences from the simulated results. The discrepancy may cause by the metal loss of the power divider and radiation waveguide as the surface roughness in the waveguide are only about $0.8 \sim 1.6 \mu \mathrm{m}$. Also, there may be some small gaps between the two parts as they are connected by 8 screws, which also will cause some loss.

The measured radiation patterns in $E$ - and $H$-plane at the center frequency $93 \mathrm{GHz}$ are compared with the simulated results in Figure 8. Thanks to the simple structure of the antenna and lower assembly requirement, the measured radiation patterns agree with the simulated results very well. The beam width in $E$-plane is about $6.5^{\circ}$ and $9^{\circ}$ in $H$-plane. The sidelobe levels in $E$-plane and $H$-plane are $-13 \mathrm{~dB}$ and $-12 \mathrm{~dB}$, respectively.
Figure 9 shows the copolarization and cross-polarization radiation patterns at 92,93 , and $94 \mathrm{GHz}$. It is clear that the radiation patterns are very similar within the working bandwidth, especially in the E-plane. All cross-polarization values shown in Figure 9 are below than $-35 \mathrm{~dB}$.

\section{Conclusion}

A waveguide slotted array at $\mathrm{W}$-band has been proposed and fabricated. All the radiation slots, radiation waveguide, and feed network of the proposed antenna are in one layer. The antenna has an effective aperture size of $24 \mathrm{~mm} \times 21 \mathrm{~mm}$. The reflection coefficient is below $-10 \mathrm{~dB}$ within 91.5-94.5 GHz, the peak gain is about $25.9 \mathrm{dBi}$, and the sidelobe levels are about $-13 \mathrm{~dB}$ in $E$-plane and $-12 \mathrm{~dB}$ in $H$ plane. The obtained results validate the proposed singlelayer technology for $\mathrm{W}$-band application featuring easy fabrication and assembly with high precision. The presented antenna is a good candidate for communication, radar, and millimeter-wave imaging applications.

\section{Data Availability}

The simulation and experimental data used to support the findings of this study are available from the corresponding author upon request.

\section{Conflicts of Interest}

The authors declare that they have no conflicts of interest.

\section{Acknowledgments}

This work was supported by the Fundamental Research Funds for the Central Universities under grants 2242019 K1G014 and 2242018K40039 and Foundation of the Key Laboratory under grants 6142502180309 and 6142502190301. 


\section{References}

[1] H. Y. Huang, B. Z. Wang, F. Li, and L. Zhao, "A Ka-band monopulse microstrip antenna array," in Proceedings of the 2008 IEEE MTT-S International Microwave Workshop Series on Art of Miniaturizing RF and Microwave Passive Components, pp. 124-127, IEEE, Chengdu, China, December 2008.

[2] G. P. Gauthier, J.-P. Raskin, L. P. B. Katehi, and G. M. Rebeiz, "A 94-GHz aperture-coupled micromachined microstrip antenna," IEEE Transactions on Antennas and Propagation, vol. 47, no. 12, pp. 1761-1766, 1999.

[3] Y. J. Cheng, Y. X. Guo, and Z. G. Liu, "W-band large-scale high-gain planar integrated antenna array," IEEE Transactions on Antennas and Propagation, vol. 62, no. 6, pp. 3370-3373, 2014.

[4] B. Liu, W. Hong, Z. Kuai et al., "Substrate integrated waveguide (SIW) monopulse slot antenna array," IEEE Transactions on Antennas and Propagation, vol. 57, no. 1, pp. 275-279, 2009.

[5] T. Li and W. B. Dou, "Millimetre-wave slotted array antenna based on double-layer substrate integrated waveguide," IET Microwaves, Antennas \& Propagation, vol. 9, no. 9, pp. 882888, 2015.

[6] D. S. Woo, K. W. Kim, and H.-C. Choi, "A broadband and high gain tapered slot antenna for W-band imaging array applications," International Journal of Antennas and Propagation, vol. 2014, Article ID 378527, 6 pages, 2014.

[7] Y. J. Cheng, W. Hong, and $\mathrm{K}$. Wu, "94 GHz substrate integrated monopulse antenna array," IEEE Transactions on Antennas and Propagation, vol. 60, no. 1, pp. 121-129, 2012.

[8] J.-C. Samuel Chieh, A.-V. Pham, A. Pidwerbetsky, and G. Kannell, "A low cost $8 \times 8 \mathrm{~W}$-Band substrate integrated waveguide antenna array detector on LCP," Microwave and Optical Technology Letters, vol. 55, no. 8, pp. 1825-1830, 2013.

[9] J. Wang and Y. J. Cheng, "W-band hybrid unequal feeding network of waveguide and substrate integrated waveguide for high efficiency and low sidelobe level slot array antenna application," International Journal of Antennas and Propagation, vol. 2017, Article ID 7183434, 8 pages, 2017.

[10] T. Li, H. F. Meng, and W. B. Dou, "Design and implementation of dual-frequency dual-polarization slotted waveguide antenna array for Ka-band application," IEEE Antenna and Wireless Propagation Letters, vol. 13, pp. 13171320, 2014.

[11] J. Hirokawa, M. Zhang, and M. Ando, "94 GHz fabrication of a slotted waveguide array antenna by diffusion bonding of laminated thin plates," in Proceedings of the IEEE Sensors Conference, pp. 907-911, Christchurch, New Zealand, October 2009.

[12] D.-Y. Kim, Y. Lim, H.-S. Yoon, and S. Nam, "High-efficiency W-band electroforming slot array antenna," IEEE Transactions on Antennas and Propagation, vol. 63, no. 4, pp. 18541857, 2015.

[13] K. Tekkouk, J. Hirokawa, K. Oogimoto et al., "Corporate-feed slotted waveguide array antenna in the $350-\mathrm{GHz}$ band by silicon process," IEEE Transactions on Antennas and Propagation, vol. 65, no. 1, pp. 217-225, 2017.

[14] D. M. Pozar, "Transmission line theory," in Microwave Engineering, pp. 57-64, John Wiley \& Sons, Hoboken, NJ, USA, 3rd edition, 2006.

[15] R. S. Elliott, "Chapter 3" in Antenna Theory and Design, Prentice-Hall, Upper Saddle River, NJ, USA, 1981. 